\title{
Hip pain in children with cerebral palsy: a population-based registry study of risk factors
}

\author{
Alexander Marcström ${ }^{*}$ (D), Gunnar Hägglund and Ann I. Alriksson-Schmidt
}

\begin{abstract}
Background: Hip pain is prevalent in children with cerebral palsy (CP). Hip displacement is a known risk factor for hip pain. However, many children do not have displaced hips but still have hip pain and the aetiologies are poorly understood. The aims of this study were to investigate: 1. the prevalence of hip pain related to age, gender, gross motor function, degree of hip displacement and 2. the associations between hip pain and age, gender, gross motor function, degree of hip displacement, ranges of hip and knee motion (ROM) and degree of spasticity in the muscles around the hip.

Methods: This was a cross-sectional retrospective register study based on data from the Swedish follow-up programme and national healthcare registry CPUP, which includes $>95 \%$ of children with CP in Sweden. The participants were born in 2000 or later and 4-16years of age. Data from the latest examination were used. In Aim 1 , the prevalence of hip pain was calculated using frequencies and crosstabs. Differences between groups were calculated using chi-square tests and independent samples t-tests. In Aim 2, associations between hip pain and the variables were analysed using logistic regression.
\end{abstract}

Results: The overall prevalence of hip pain was 7\%. No significant gender difference was found. Hip pain prevalence increased with age, lower gross motor function and higher degree of hip displacement. The median migration percentage (MP) in painful hips was $26 \%$, compared to $21 \%$ in hips where pain was not reported. In the multivariable analysis, significant associations with hip pain were found for MP $>30 \%$ and decreased ROM in abduction, flexion and inwards rotation of the hip $(p<0.05)$.

Conclusion: Hip displacement was associated with hip pain. However, hip displacement was not present in the majority of painful hips. In addition to hip displacement, decreased ROM was also associated with hip pain.

Keywords: Cerebral palsy, Hip, Pain, Register, Risk factors

\section{Background}

Cerebral palsy $(\mathrm{CP})$ is a heterogeneous group of permanent disorders of movement and posture appearing in early childhood. The severity, type and site of the movement and posture impairments vary widely. $\mathrm{CP}$ is often, especially in more severe cases, accompanied by additional impairments such as those of communication, sensation or cognition [1]. Secondary conditions, which per definition are preventable, are also common [2]. Pain

\footnotetext{
* Correspondence: alexandermarcstrom@gmail.com

Lund University, Skåne University Hospital, Department of Clinical Sciences Lund, Orthopedics, Lund, Sweden
}

is one of the more frequent secondary conditions in $\mathrm{CP}$. A systematic review showed that three of four children with CP were in pain [3]. Pain has been found to reduce both self-reported quality of life and participation in life situations $[4,5]$.

Gross motor function is often described with the gross motor function classification system (GMFCS), consisting of five levels, where level $\mathrm{V}$ describes the most impaired gross motor function [6]. There are conflicting results regarding the association between pain and gross motor function. Some studies report no association [4, 7], while others report higher frequency of pain in children with lower gross motor function $[8,9]$. In a recent 
registry study on pain including 2777 children with CP in Sweden, pain sites differed according to the GMFCS. Pain in the feet was most commonly reported at GMFCS I, knee pain at GMFCS III and abdominal and hip pain at GMFCS V [10]. Several studies have found that girls with CP report pain more frequently than boys, which is in line with gender differences found in the general population [9-11]. In addition, the frequency of pain generally increases significantly with age in this population. [9] Spasticity and decreased range of motion $(\mathrm{ROM})$ are other factors that have been associated with pain in individuals with CP $[12,13]$.

One of the most common pain sites in children with $\mathrm{CP}$ is the hips [10]. The aetiologies of hip pain are not clear, yet some factors are known to be related. The majority of children with severely displaced or dislocated hips experience hip pain [14]. The risk of developing hip displacements and dislocations increases with lower gross motor function [15], and hip pain is also more frequently reported in children with lower gross motor function (i.e., higher GMFCS level) [10]. Displacements and dislocations of the hips can largely be prevented [16, 17]. Since the introduction of hip surveillance in Sweden in 1994, the incidence of hip dislocations in children with $\mathrm{CP}$ has decreased from $8 \%$ to a stable $0.4 \%$ [17]. However, despite progress in preventing hip dislocations, $19 \%$ of children with the lowest gross motor function and $9 \%$ of all children with CP at any GMFCS level experience hip pain in Sweden, making it the second most common location of pain, after pain in the feet [10].

The aims of this study were to investigate: 1 . The prevalence of hip pain related to age, gender, GMFCS level and degree of hip displacement. 2. The associations between hip pain and age, gender, GMFCS level, degree of hip displacement, ranges of passive hip and knee motion and degree of spasticity in different muscle groups around the hip.

\section{Methods}

This was a cross-sectional retrospective cohort study based on registry data from January 2015 - October 2017.

\section{Procedure and participants}

This study was based on data from the Cerebral Palsy Follow-Up Programme (CPUP). CPUP is a combined multidisciplinary longitudinal follow-up programme and registry for individuals with $\mathrm{CP}$. Since 2005 , the registry is classified as a Swedish national quality registry by the Swedish government, including 95\% of children with CP in Sweden born after 2000 [18]. Children with suspected or confirmed diagnoses of $\mathrm{CP}$ are invited to participate in CPUP. Before deciding to participate, the legal caregivers are informed that it is possible to withdraw their child from the registry at any time, and that doing so will not affect their children's healthcare. They are also informed that it is possible to partake in the follow-up program only, and not in the registry. Verbal consent is obtained by the legal caregivers who agree to their children's participation. By the age of four years, a neuropaediatrician either confirms or dismisses the $\mathrm{CP}$ diagnosis. If the diagnosis is dismissed, the child's data are deleted from the registry. The children with confirmed diagnoses continue to be regularly assessed using a standardized protocol by physiotherapists (PT) and occupational therapists at the habilitation units, and the data are electronically entered into the registry. Depending on the age and the gross motor function, the examination schedule varies from two times per year to once every second year (Fig. 1). This study included data from

\section{Age}

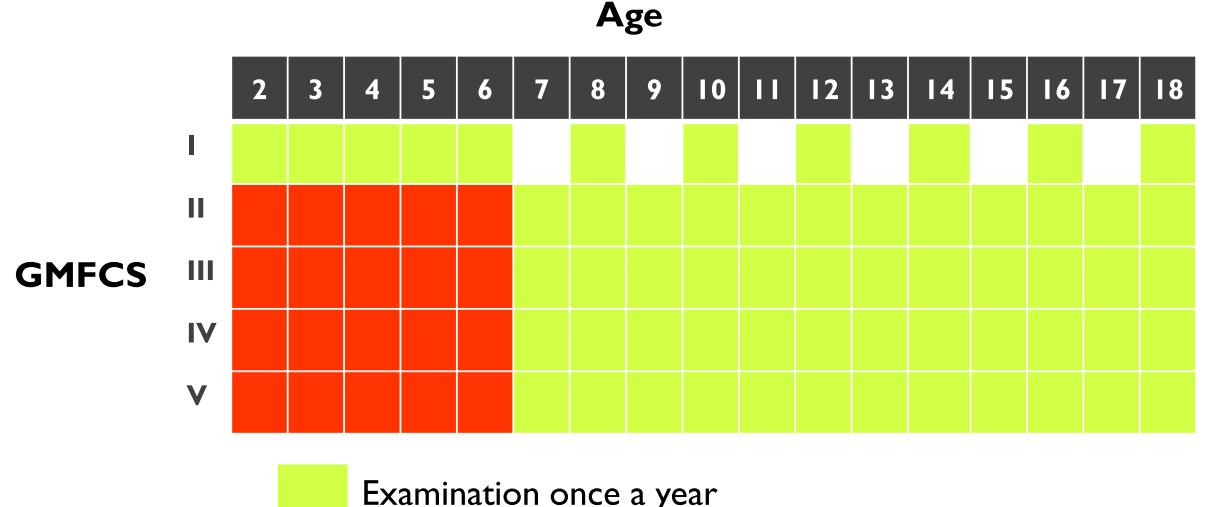

Examination once a year

\section{Examination twice a year}

Fig. 1 Clinical examination schedule in the Swedish surveillance programme for individuals with CP (CPUP). GMFCS = Gross Motor Function Classification System 
the latest assessment for children in CPUP aged 4-16 years and born after 2000. Children with baclofen pumps and/or missing data on pain variables were excluded.

The study was approved by the Ethics Board at Lund University (LU 443-99, revised 2009).

\section{Measures}

Age was measured as a continuous variable (whole years) and gender as a dichotomous variable. Gross motor function was measured using the GMFCS Expanded \& Revised Version (referred to as GMFCS in this report), which replaced the original GMFCS system in 2007 and expanded the age range to also include 12- to 18-year-olds [6]. The GMFCS describes the child's gross motor function on a 5-level ordinal scale, where level I indicates the highest and level $\mathrm{V}$ the lowest gross motor function. The GMFCS has been shown to have good inter-/intra-rater reliability and stability [19-21]; and is also valid in terms of describing actual motor ability, e.g., it correlates well with ability in activities of daily living [12].

The degree of hip displacement was measured on radiographs with the migration percentage (MP) [22]. The MP ranges from 0 to $100 \%$ and measures the proportion of the femoral head positioned lateral to the acetabular margin (Fig. 2). At 100\%, the hip is dislocated. In CPUP, children at GMFCS II-V undergo regular radiographic hip examinations, usually once a year (Fig. 3). For children at GMFCS I, radiographic hip examinations are

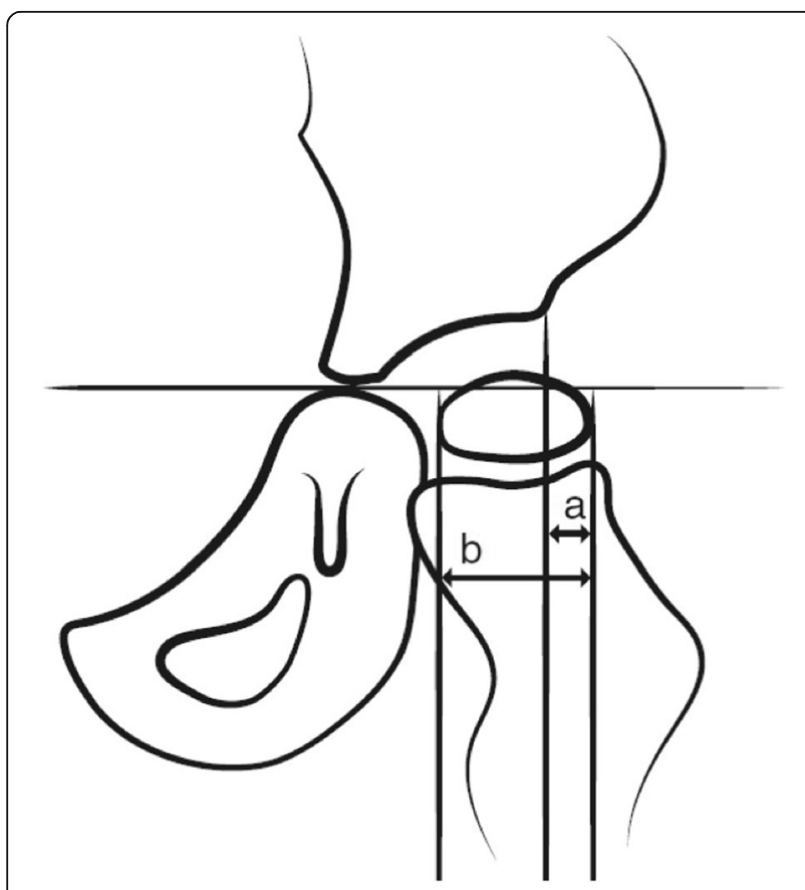

Fig. 2 Measurement of the hip migration percentage (MP). MP = a / b $\times 100$. GMFCS $=$ Gross Motor Function Classification System performed only in children with abnormal values at the PT examinations or if the child experiences hip pain.

Degree of spasticity was classified with the Modified Ashworth Scale (MAS), a 6-level ordinal scale ranging from 0 to 4 [23]. Moderate to high inter- and intra-rater reliabilities were reported in a recent meta-analysis, with higher reliability for upper than lower extremities [24]. For the purpose of this study, those with scores of 1 or 1 + were combined into one group. Degrees of spasticity in the following five muscle groups were included: Hip flexors, hip extensors, hip adductors, knee flexors and knee extensors. ROM was measured as a continuous variable with goniometer in a standardised position according to the CPUP-manual [25]. The ROM values were rounded to the closest multiple of five and analysed in seven ranges: hip flexion, hip extension, hip abduction, knee extension with the hip straight, knee extension with the hip in $90^{\circ}$ flexion and inwards and outwards rotation of the hip. The presence of pain was recorded as a dichotomous variable (pain/no pain). During the PT examination, the child or caregiver (proxy) was asked "are you or do you know/think that the child is in pain?". If yes, checkboxes were ticked for ten different body locations to indicate the pain site. Since 2016, it is also recorded whether the pain items were self- or proxy reported. If all pain items were left blank, the child was excluded from analysis.

Information on previous hip surgeries were recorded and classified into three groups: (I) Soft tissue surgery (adductor - psoas lengthening), (II) femur osteotomy and (III) pelvic osteotomy. It should be noted that soft tissue surgery could be performed by itself (coded I), however femur osteotomy (coded as II) was always performed in combination with soft tissue surgery, and pelvis osteotomy (coded as III), in turn, was always performed in combination with soft tissue surgery and femur osteotomy. Administration of spasticity-reducing botulinum toxin A in the lower extremities since the latest examination was recorded as yes or no.

\section{Statistical analysis}

It is not recorded in CPUP if the pain was in the right, left or both hips. If assuming pain in both hips and including both in the analyses, the assumption of independence between observations would be violated [26]. Therefore, for every measure, data from only one hip per participant was used. This was done systematically; for each participant and for each measure, the most spastic muscle group, the lowest recorded ROM and the highest recorded MP were used. An alternative would have been to use the mean value of both hips in all participants. This was considered a less ideal option given the large differences between sides in children with unilateral spastic CP. 


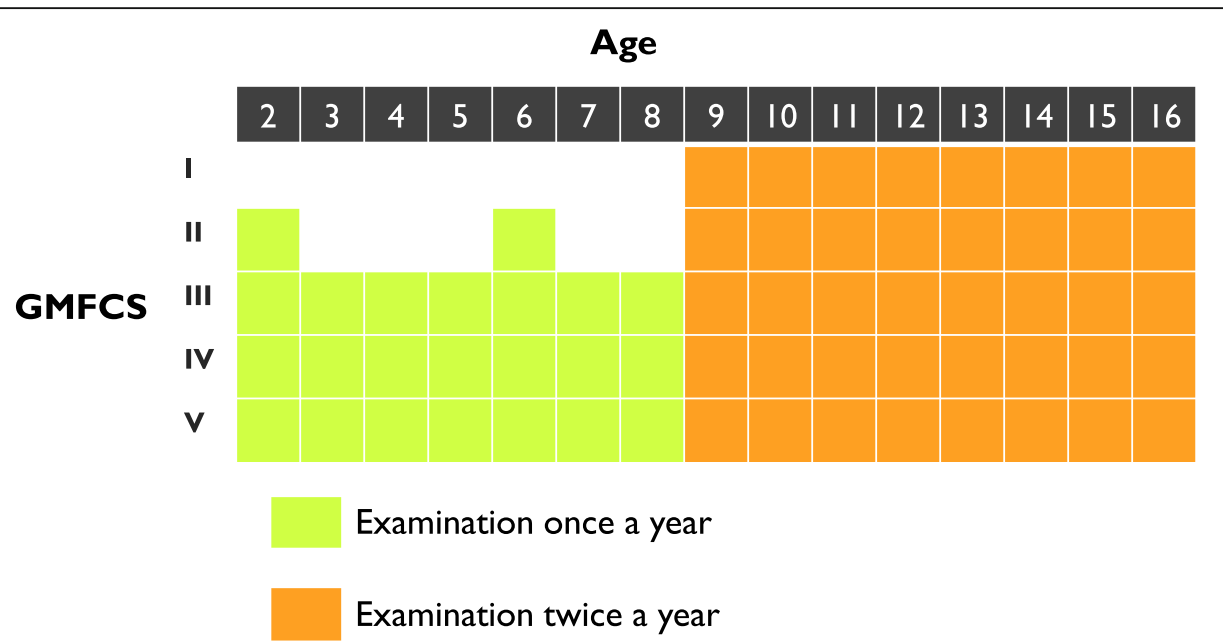

Fig. 3 Radiographic examination schedule in the Swedish surveillance programme for individuals with CP (CPUP). GMFCS = Gross Motor Function Classification System ROM = Range of motion

In Aim 1, the prevalence of pain was calculated using frequencies and crosstabs. Chi-squares and independent-samples t-test were used to assess differences between groups. In Aim 2, binomial logistic regressions were employed to evaluate the associations between the dependent variable (hip pain) and the independent variables. Linear regression was used to test for multicollinearity, with all variables having lower variance inflation factors than 2.0. All variables were linear to the logit of hip pain and were therefore included. All studentized residuals were kept in the analyses. Nagelkerke $\mathrm{R}^{2}$ was used to describe the variance in hip pain explained by the model. Listwise deletion was used, meaning that only children with values for all variables were included in the logistic regression. Children with missing data on spasticity, ROM or hip displacement were therefore excluded. Due to small cell sizes, MAS levels 3 and 4 were combined, and MPs were grouped accordingly: $0-30 \%, 31-40 \%$ and $41-100 \%$. Because the indication for radiographic examinations of the hips differ between GMFCS I and the other levels, children at GMFCS I were not included in the primary logistic regression analysis. To be able to generalize the results to children at all GMFCS levels however, a complementary logistic regression analysis was employed, including children at all GMFCS levels without hip displacement as an independent variable, presented in Additional files. Significance was considered at $0.05 \%$ level. IBM SPSS Statistics version 24 was used for statistical analysis [27].

\section{Results}

A total number of 3088 children met the inclusion criteria. Of these, 198 children had baclofen pumps and/or missing data on pain and were excluded. This did not affect the distribution of gender, age, or GMFCS levels significantly. An inclusion flowchart is presented in Fig. 4. Characteristics of the participants included in the different analyses are shown in Table 1 . Pain items were self-reported in $51 \%$ of children and proxy reported in $49 \%$. In total, $12 \%$, had undergone soft tissue surgery, femoral osteotomy and/or pelvic osteotomy (GMFCS I $=1 \%$, GMFCS II $=3 \%$, GMFCS III $=14 \%$, GMFCS IV $=$ $27 \%$, and GMFCS V $=46 \%$ ). Children with higher gross motor function (i.e., lower GMFCS levels) and older ages were more likely to self-report. Characteristics of

Children in CPUP

Born after 2000, 4-16 years $(n=3088)$

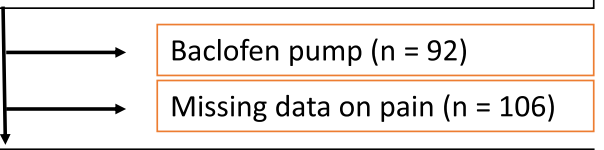

Aim 1 - Prevalence of hip pain related to:

Age, gender and GMFCS level $(n=2890)$

\begin{tabular}{|l|l|}
\hline & \multicolumn{1}{|c|}{$\begin{array}{l}\text { Missing data on hip } \\
\text { displacement }(n=1170)\end{array}$} \\
\hline $\begin{array}{l}\text { Aim } 1 \text { - Prevalence of hip pain related to: } \\
\text { Degree of hip displacement }(\mathrm{n}=1720)\end{array}$ \\
\hline
\end{tabular}

Fig. 4 Inclusion flowchart. GMFCS = Gross Motor Function Classification System ROM = Range of motion 
Table 1 Characteristics of the study population

\begin{tabular}{lll}
\hline Characteristics & Aim 1 ${ }^{\text {a }}$ & Aim 2 $^{\text {b }}$ \\
\hline Total, $n$ & 2890 & 952 \\
Age, mean (SD) & $9.5(3.6)$ & $9.6(3.6)$ \\
Sex, n (\%) & & \\
$\quad$ Boys & $1660(57.4)$ & $572(60.1)$ \\
$\quad$ Girls & $1230(42.6)$ & $380(39.9)$ \\
GMFCS level, n (\%) & & \\
I & $1327(45.9)$ & $0(0.0)$ \\
II & $489(16.9)$ & $277(29.1)$ \\
III & $266(9.2)$ & $180(18.9)$ \\
IV & $423(14.6)$ & $290(30.5)$ \\
V & $385(13.3)$ & $205(21.5)$ \\
BTX-A treatment since last assessment, n (\%) & $563(19.5)$ & $254(26.7)$ \\
Hip Surgery, n (\%) & & \\
Soft tissue & $143(4.9)$ & $83(8.7)$ \\
Femur osteotomy & $104(3.6)$ & $61(6.4)$ \\
Pelvic osteotomy & $107(3.7)$ & $64(6.7)$ \\
Pain, n (\%) & & \\
Any site & $1127(39.0)$ & $375(39.4)$ \\
Hip pain & $202(7.0)$ & $86(9.0)$ \\
\hline GMFS Gross Motor Funcion Cassication Systen & &
\end{tabular}

GMFCS Gross Motor Function Classification System BTX-A Botulinum Toxin A

${ }^{\text {a Aim 1: Prevalence analysis }}$

${ }^{\mathrm{b}}$ Aim 2: Association analysis children who self-reported and those who did not (i.e. proxy reported) are presented in Additional file 1.

In total, 2890 children were included in the prevalence analysis (Aim 1). Pain at any site was reported in 1127 children (39.0\%) and hip pain was reported in 202 children (7.0\%). In the self-reporting group, $5.3 \%$ of the children reported having hip pain (any pain $=40.2 \%$ ), compared to $8.8 \%$ (any pain $=34.7 \%$ ) in the proxy reported group. The prevalence of hip pain was $7.5 \%$ in girls and $6.7 \%$ in boys, a non-significant difference. The prevalence increased with age and GMFCS level (Figs. 5 and 6). In the prevalence analysis related to hip displacement, data were available in 1720 children. The hip pain prevalence increased with increasing MP (Fig. 7). The median MP in painful hips was $26 \%$, compared to $21 \%$ in hips where pain was not reported.

A total of 952 children were included in the association analysis (Aim 2). The model explained $28 \%$ of the variance of hip pain. The results are presented in Table 2. The odds ratio (OR) did not differ significantly with increasing age or for girls compared to boys. Compared to children at GMFCS II, children at GMFCS III and IV did not have significantly higher ORs for hip pain and the OR for children at GMFCS $\mathrm{V}$ was 2.40 (95\% CI $=0.97-5.96)$. Compared to spasticity level 0 , none of the five muscle groups around the hip had significant ORs on hip pain, except for level 2 in knee extensors. The OR of hip pain was significantly higher for decreased ROM with 5 degrees in three out of seven directions; inward rotation, flexion and abduction of the hip. Compared to MP

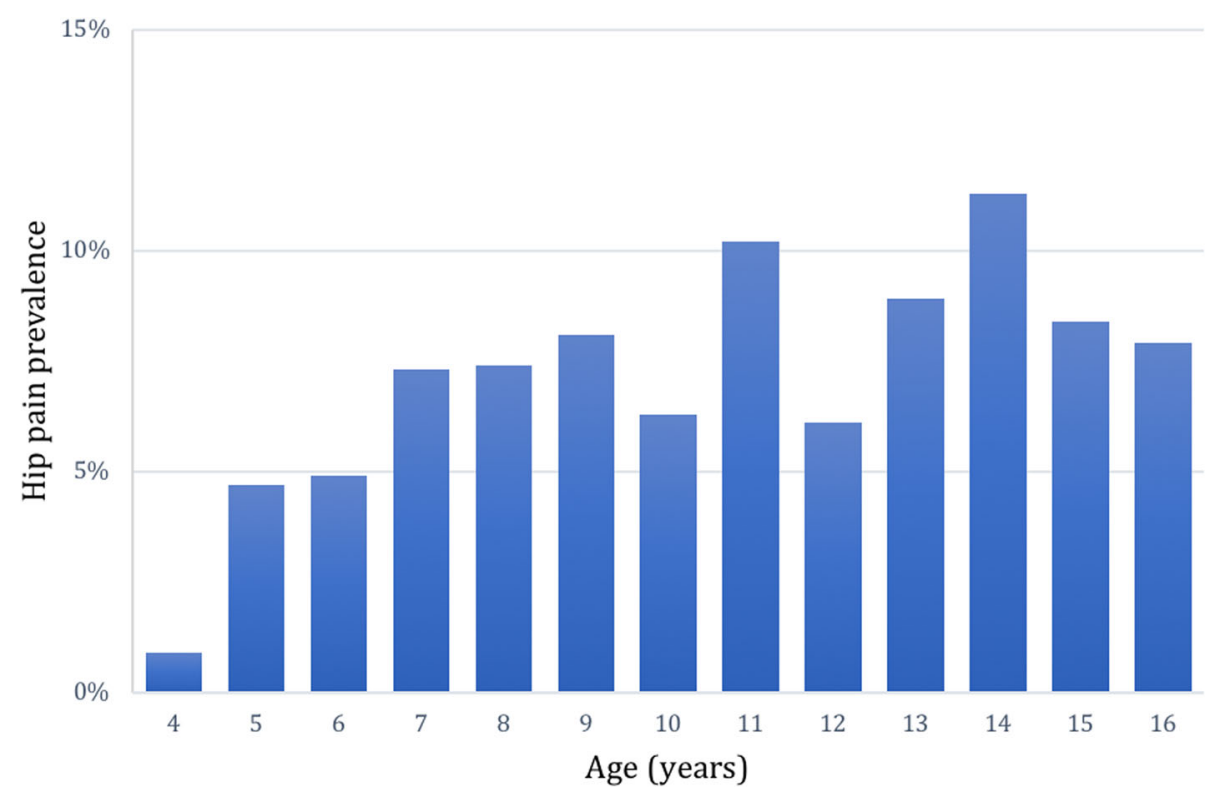

Fig. 5 Hip pain prevalence related to age $(n=2890)$ 


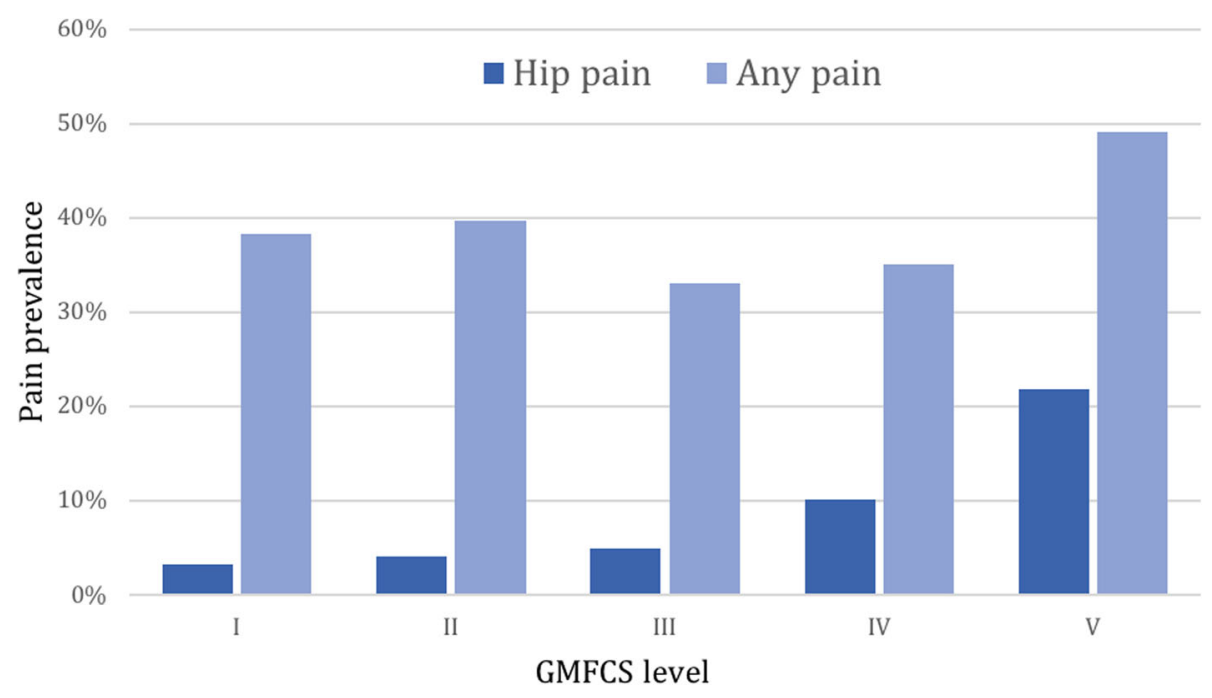

Fig. 6 Prevalence of hip pain and pain at any site (including hip pain) related to GMFCS level $(n=2890)$. GMFCS = Gross Motor Function Classification System

$0-30 \%$, the OR for hip pain was $2.11(95 \% \mathrm{CI}=1.10$ 4.06) for MP $31-40 \%$ and $2.72(95 \% \mathrm{CI}=1.32-5.59)$ for MP $41-100 \%$.

The additional analysis, with children at all GMFCS levels included $(n=2224)$ and without MP as an independent variable, is presented in Additional file 2. The same pattern as in the main analysis was found for age, gender and spasticity. Children at GMFCS V had significantly higher OR of hip pain than children at level I. The OR were significantly higher for decreased ROM in flexion and abduction of the hip.

\section{Discussion}

We studied the prevalence of hip pain related to age, gender and gross motor function level, and the associations between hip pain and; age, gender, gross motor function level, range of hip and knee motion, spasticity in the muscles around the hip joint and degree of hip displacement. The main findings were that hip displacement and lower range of motion, but not spasticity, were associated with hip pain.

The prevalence of hip pain and pain at any site was similar to other studies based on CPUP data $[10,28]$, and less than half compared to the population-based

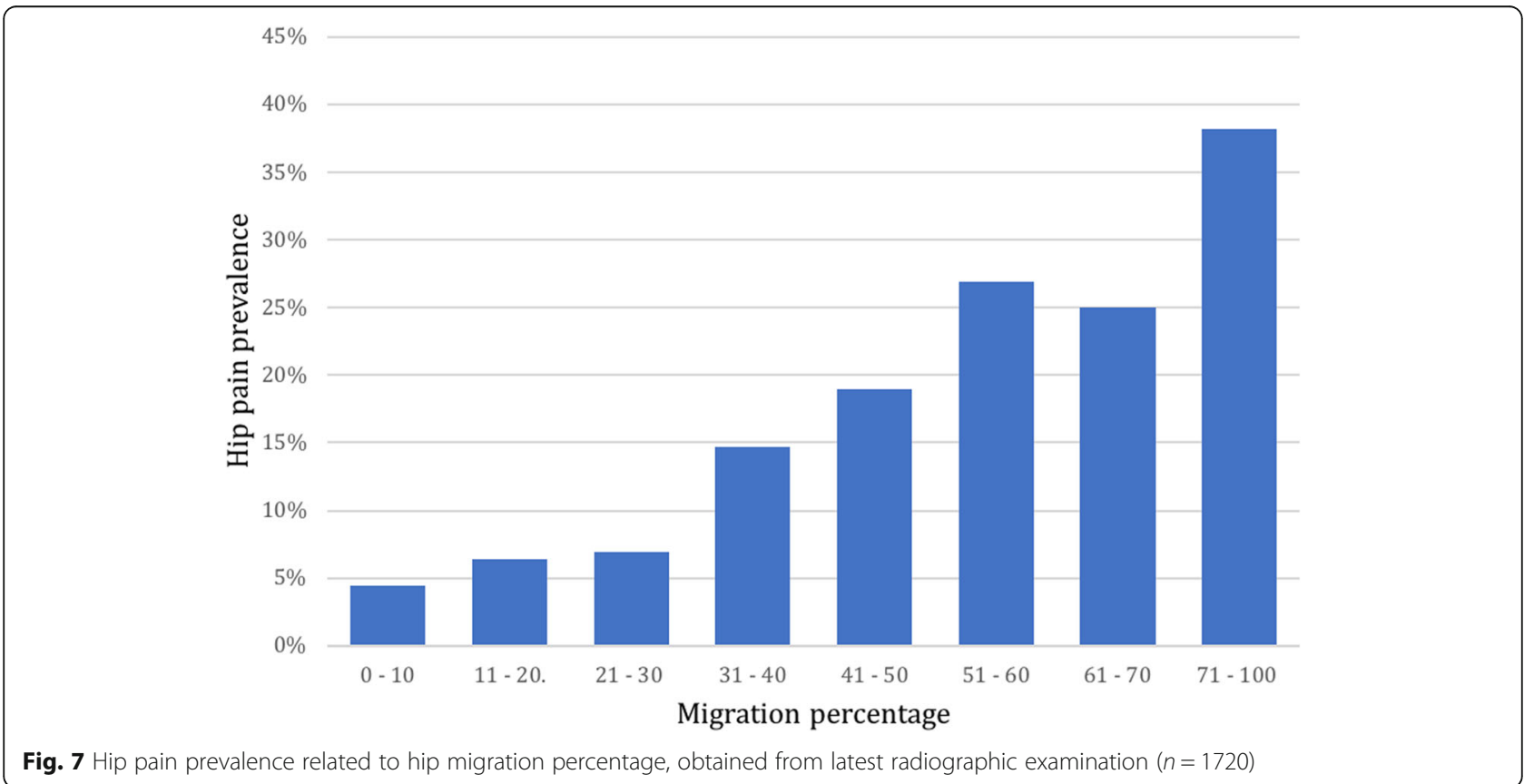


Table 2 Logistic regression with hip pain as dependent variable. $N=952$

\begin{tabular}{|c|c|c|c|c|}
\hline \multirow{2}{*}{$\begin{array}{l}\overline{\text { Variable }} \\
\text { Age }^{\mathrm{a}}\end{array}$} & \multicolumn{2}{|c|}{ Hip pain / sample size (\%) ${ }^{d}$} & \multicolumn{2}{|c|}{ Odds Ratio (95\% Cl) } \\
\hline & 952 & & 1.0 & $(0.92-1.09)$ \\
\hline \multicolumn{5}{|l|}{ Gender } \\
\hline Male & $46 / 572$ & $(8.0)$ & 1.0 & \\
\hline Female & $40 / 380$ & $(10.5)$ & 1.21 & $(0.72-2.05)$ \\
\hline \multicolumn{5}{|l|}{ GMFCS } \\
\hline$\|$ & $11 / 277$ & $(4.0)$ & 1.0 & \\
\hline III & $10 / 180$ & (5.6) & 1.04 & $(0.40-2.67)$ \\
\hline IV & $23 / 290$ & (7.9) & 1.10 & $(0.46-2.68)$ \\
\hline V & $42 / 205$ & $(20.5)$ & 2.40 & $(0.97-5.96)$ \\
\hline \multicolumn{5}{|l|}{ Spasticity $^{b}$} \\
\hline Hip flexors level 0 & $41 / 670$ & $(6.1)$ & 1.0 & \\
\hline level 1 & $36 / 230$ & $(15.7)$ & 1.50 & $(0.83-2.72)$ \\
\hline level 2 & $2 / 31$ & (6.5) & 0.54 & $(0.09-3.25)$ \\
\hline levels 3-4 & $7 / 21$ & $(33.3)$ & 3.55 & $(0.82-15.41)$ \\
\hline Hip extensors level 0 & $40 / 644$ & $(6.2)$ & 1.0 & \\
\hline level 1 & $33 / 216$ & $(15.3)$ & 1.0 & $(0.52-1.93)$ \\
\hline level 2 & $8 / 64$ & $(12.5)$ & 0.36 & $(0.11-1.16)$ \\
\hline levels 3-4 & $5 / 28$ & $(17.9)$ & 0.38 & $(0.08-1.83)$ \\
\hline Hip adductors level 0 & $17 / 385$ & $(4.4)$ & 1.0 & \\
\hline level 1 & $39 / 387$ & $(10.1)$ & 1.86 & $(0.91-3.83)$ \\
\hline level 2 & $18 / 128$ & $(14.1)$ & 1.73 & $(0.69-4.33)$ \\
\hline levels 3-4 & $12 / 52$ & $(23.1)$ & 2.87 & $(0.91-8.99)$ \\
\hline Knee flexors level 0 & $16 / 275$ & $(5.8)$ & 1.0 & \\
\hline level 1 & $43 / 458$ & (9.4) & 0.80 & $(0.38-1.69)$ \\
\hline level 2 & $14 / 156$ & (9.0) & 0.65 & $(0.26-1.63)$ \\
\hline levels 3-4 & $13 / 63$ & (20.6) & 0.96 & $(0.30-3.09)$ \\
\hline Knee extensors level 0 & $36 / 592$ & $(6.1)$ & 1.0 & \\
\hline level 1 & $26 / 265$ & $(9.8)$ & 0.69 & $(0.36-1.33)$ \\
\hline level 2 & $15 / 65$ & $(23.1)$ & 2.81 & $(1.18-6.69)$ \\
\hline levels 3-4 & $9 / 30$ & $(30.0)$ & 0.84 & $(0.20-3.56)$ \\
\hline \multicolumn{5}{|l|}{ Range of motion ${ }^{c}$} \\
\hline Knee Extension & 952 & & 0.97 & $(0.85-1.10)$ \\
\hline Hamstring & 952 & & 0.93 & $(0.84-1.02)$ \\
\hline Hip inward rotation & 952 & & 1.11 & $(1.01-1.20)$ \\
\hline Hip outward rotation & 952 & & 0.95 & $(0.88-1.04)$ \\
\hline Hip Extension & 952 & & 1.09 & $(0.96-1.25)$ \\
\hline Hip Flexion & 952 & & 1.18 & $(1.05-1.32)$ \\
\hline Hip Abduction & 952 & & 1.20 & $(1.04-1.41)$ \\
\hline \multicolumn{5}{|l|}{ Hip migration percentage } \\
\hline $0-30$ & $46 / 721$ & (6.4) & 1.0 & 1.0 \\
\hline $31-40$ & $19 / 147$ & (12.9) & 2.11 & $(1.1-4.06)$ \\
\hline $41-100$ & $21 / 84$ & $(25.0)$ & 2.72 & $(1.32-5.59)$ \\
\hline
\end{tabular}

GMFCS Gross Motor Function Classification System

Cl Confidence Interval

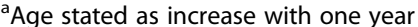

${ }^{\mathrm{b}}$ Spasticity classified according to the Modified Ashworth Scale with levels 3 and 4 grouped together

'Range of motion stated as decrease with five degrees

${ }^{d}$ For continuous variables (age and range of motion), only sample size is presented 
SPARCLE study, conducted in seven European countries [9]. This was also the case for the prevalence of pain at any site, which was almost twice as common in the SPARCLE study. In the SPARCLE study, 54\% of the children between 8 and 12 years experienced pain in the previous week, [4] a percentage that increased to $74 \%$ in a follow up at 13-17 years [9]. Differences in age structure and GMFCS distribution between the two studies might explain some of the differences. Less sensitive pain screening in CPUP, without specified recall time when asking about pain, might also help explain the differences. However, the lower pain prevalence might, to some extent, be contributed to successful prevention of secondary musculoskeletal complications in CPUP [17]. As expected, proxy reports were more common in younger children and for children with lower motor ability. Hip pain was more frequently reported in the proxy reported group than the self-reported group. Part of the reason for this could be that the prevalence of hip pain is higher in children at higher GMFCS levels, and that children reported by proxy generally were at higher GMFCS levels. However, to report on somebody else's pain is difficult.

There was a trend of increasing prevalence of hip pain with increasing age. However, in the multivariable analysis, no significant association was found. This differs from what is usually observed for pain in this population where pain and age are generally positively associated [13]. Regarding gender, there was no significant difference in hip pain prevalence and no association with hip pain in the multivariable analyses. The lack of age and gender effects on hip pain specifically have been observed previously [14].

The prevalence of hip pain at GMFCS IV and V was higher than at GMFCS I-III. In the multivariable analysis, with children at GMFCS II as reference, only being at GMFCS V was borderline significantly associated with hip pain. In the additional analysis, with children at GMFCS I as reference, being at GMFCS V was significantly associated with hip pain. Possible causes are inactivity, extended periods of time spent in the same position or poor positioning. As the majority in this group did not answer the pain items themselves, it is also possible that the proxy reporters misinterpreted the pain or the pain site, e.g. abdominal pain might have been interpreted as hip pain or vice versa.

There was a trend of increasing prevalence of hip pain with higher MPs. Compared to MP 0-30, the OR for hip pain were significantly higher at MP $31-40 \%$ and $41-$ $100 \%$. An association between hip pain and MP $>50 \%$ has previously been found in children with CP [14]. In adults with $\mathrm{CP}$, associations between hip pain and $\mathrm{MP} \geq$ 33 has been found [29]. Our study confirms the association between hip pain and higher MPs and implies that the risk for hip pain is increased already from the 31-40 range. In Sweden, surgeries to prevent hip dislocations are sometimes recommended in children with MP > $33 \%$. Our findings do indicate that pain seems to occur at low MPs and that interventions should be considered early to prevent pain. However, the majority of painful hips had $\mathrm{MP}<30 \%$, indicating that other factors than hip displacement also drive hip pain.

Decreased ROMs in abduction, flexion and inwards hip rotation of the hip were significantly associated with hip pain. The association between hip pain and decreased ROM has previously been reported in adults with CP [12]. One possible explanation is that decreased ROM causes painful strenuous movement patterns and body positions. It is also possible that children with decreased ROMs are closer to their maximum ROM for longer periods and that this causes pain. However, it is also likely that the maximum ROM is not measured in a painful hip.

Higher spasticity level was not significantly associated with hip pain for any muscle group, except for MAS level 2 in knee extensors. However, wide confidence intervals and absence of significant associations for the other spasticity levels in this muscle group implies that the association could be due to chance and not clinically important. Association between pain and spasticity is not well substantiated in the literature. Children with spastic $\mathrm{CP}$ have not been found to report pain more frequently than children with other subtypes [28]. However, spasticity has been related to deterioration in ROM during growth and as such might indirectly affect pain [30].

As this was a cross sectional study, causality cannot be inferred. The pain items in CPUP were created to mainly screen for pain. More information of the pain experience is needed and to that end, more detailed pain items have now been included in CPUP. The lack of data on side of body, type, intensity and duration of pain limited the analysis. Due to some of the children's comorbidities and/or young age/s, self-report was not always possible. The effect of proxy reports is unclear, in other studies both underand over reporting of pain have been reported [13, 31]. It should be noted that it is very difficult to know for sure that the pain came from the hip joint even if that is where the pain seemed to originate. It is possible that the pain radiated from other areas, such as the stomach or the spine. Moreover, with respect to generalizability, the rather low MP reported in children with $\mathrm{CP}$ in Sweden might limit this to populations with similarly low MPs.

The major strengths of this study come from the large cohort analysed, including almost all children with $\mathrm{CP}$ in Sweden at all GMFCS levels. Since almost the entire population of children with $\mathrm{CP}$ were included, there is 
little risk for selection bias and our results are likely generalizable.

\section{Conclusion}

Hip displacement was associated with hip pain. However, hip displacement was not present in the majority of painful hips. In addition to hip displacement, it was found that decreased ROM was associated with hip pain.

\section{Additional files}

Additional file 1: Characteristics of children who self-reported and those who did not (i.e. proxy reported) (DOCX $13 \mathrm{~kb}$ )

Additional file 2: Logistic regression, with children at all GMFCS levels included $(n=2224)$ and without MP as an independent variable (DOCX $16 \mathrm{~kb}$ )

\section{Abbreviations}

CP: Cerebral palsy; CPUP: Swedish cerebral palsy surveillance program and national quality registry; MAS: Modified Ashworth Scale; MP: Migration percentage; PT: Physiotherapist; ROM: Range of motion

\begin{abstract}
Acknowledgements
The authors would like to thank biostatistician Tomasz Czuba for statistical assistance. Furthermore, the authors would like to express their gratitude to Sunnerdahls Handikappsstiftelse, the Linnea and Josef Carlsson Foundation, the Norrbacka-Eugenia Foundation, Jerringfonden, Riksförbundet för Rörelsehindrade Barn och Ungdomar (RBU), and Stiftelsen för bistånd åt rörelsehindrade i Skåne for their continued support on research related to pain in children and adolescents with cerebral palsy.
\end{abstract}

\section{Funding}

Not applicable.

\section{Availability of data and materials}

Data used in this study are stored at the National Quality Registry CPUP http://rcsyd.se/anslutna-register/cpup. Data are not publicly available and permission to extract data can be obtained from the registry holder.

\section{Authors' contributions}

AAS and GH designed the study. AM and GH extracted the data. AM performed the statistical analysis and drafted the manuscript. AAS and GH revised and improved the manuscript. All authors approved the final draft.

\section{Ethics approval and consent to participate}

The study was approved by the Ethics Board at Lund University (LU 443-99, revised 2009). All families had given verbal consent to use data for research before inclusion in the CPUP registry. Permission to extract data from the CPUP registry was obtained.

\section{Consent for publication}

Not applicable.

\section{Competing interests}

The authors declare that they have no competing interests.

\section{Publisher's Note}

Springer Nature remains neutral with regard to jurisdictional claims in published maps and institutional affiliations.

Received: 24 April 2018 Accepted: 1 February 2019 Published online: 08 February 2019

\section{References}

1. Colver A, Fairhurst C, Pharoah POD. Cerebral palsy. Lancet. 2014;383(9924): 1240-9.
2. Simeonsson RJ, McMillen JS, Huntington GS. Secondary conditions in children with disabilities: spina bifida as a case example. Ment Retard Dev Disabil Res Rev. 2002;8(3):198-205.

3. Novak I, Hines M, Goldsmith S, Barclay R. Clinical prognostic messages from a systematic review on cerebral palsy. Pediatrics. 2012;130(5): e1285-312.

4. Dickinson HO, Parkinson KN, Ravens-Sieberer U, Schirripa G, Thyen U, Arnaud C, et al. Self-reported quality of life of 8-12-year-old children with cerebral palsy: a cross-sectional European study. Lancet. 2007;369(9580):2171-8.

5. Fauconnier J, Dickinson HO, Beckung E, Marcelli M, McManus V, Michelsen SI, et al. Participation in life situations of 8-12 year old children with cerebral palsy: cross sectional European study. BMJ. 2009;338:b1458.

6. Palisano RJ, Rosenbaum P, Bartlett D, Livingston MH. Content validity of the expanded and revised gross motor function classification system. Dev Med Child Neurol. 2008;50(10):744-50.

7. Kennes J, Rosenbaum P, Hanna SE, Walter S, Russell D, Raina P, et al. Health status of school-aged children with cerebral palsy: information from a population-based sample. Dev Med Child Neurol. 2002;44(4):240-7.

8. Houlihan CM, O'Donnell M, Conaway M, Stevenson RD. Bodily pain and health-related quality of life in children with cerebral palsy. Dev Med Child Neurol. 2004:46(5):305-10.

9. Parkinson KN, Dickinson HO, Arnaud C, Lyons A, Colver A. Pain in young people aged 13 to 17 years with cerebral palsy: cross-sectional, multicentre European study. Arch Dis Child. 2013;98(6):434-40.

10. Alriksson-Schmidt A, Hagglund G. Pain in children and adolescents with cerebral palsy: a population-based registry study. Acta Paediatr. 2016;105(6): 665-70.

11. Brun Sundblad GM, Saartok T, Engström LM. Prevalence and co-occurrence of self-rated pain and perceived health in school-children: age and gender differences. Eur J Pain. 2007;11(2):171-80.

12. Sandström K, Alinder J, Öberg B. Descriptions of functioning and health and relations to a gross motor classification in adults with cerebral palsy. Disabil Rehabil. 2004;26(17):1023-31.

13. Penner M, Xie WY, Binepal N, Switzer L, Fehlings D. Characteristics of pain in children and youth with cerebral palsy. Pediatrics. 2013;132(2):e407-13.

14. Ramstad K, Terjesen T. Hip pain is more frequent in severe hip displacement: a population-based study of 77 children with cerebral palsy. J Pediatr Orthop B. 2016;25(3):217-21.

15. Hermanson M, Hägglund G, Riad J, Rodby-Bousquet E, Wagner P. Prediction of hip displacement in children with cerebral palsy: development of the CPUP hip score. Bone Joint J. 2015;97-B(10):1441-4.

16. Elkamil Al, Andersen GL, Hägglund G, Lamvik T, Skranes J, Vik T. Prevalence of hip dislocation among children with cerebral palsy in regions with and without a surveillance programme: a cross sectional study in Sweden and Norway. BMC Musculoskelet Disord. 2011;12:284.

17. Hägglund G, Alriksson-Schmidt A, Lauge-Pedersen H, Rodby-Bousquet E, Wagner $\mathrm{P}$, Westbom L. Prevention of dislocation of the hip in children with cerebral palsy: 20-year results of a population-based prevention programme. Bone Joint J. 2014:96-B(11):1546-52.

18. Alriksson-Schmidt Al, Arner M, Westbom L, Krumlinde-Sundholm L, Nordmark E, Rodby-Bousquet E, et al. A combined surveillance program and quality register improves management of childhood disability. Disabil Rehabil. 2017;39(8):830-6.

19. Wood E, Rosenbaum P. The gross motor function classification system for cerebral palsy: a study of reliability and stability over time. Dev Med Child Neurol. 2000;42(5):292-6.

20. Alriksson-Schmidt A, Nordmark E, Czuba T, Westbom L. Stability of the gross motor function classification system in children and adolescents with cerebral palsy: a retrospective cohort registry study. Dev Med Child Neurol. 2017;59(6):641-6.

21. Palisano RJ, Cameron D, Rosenbaum PL, Walter SD, Russell D. Stability of the gross motor function classification system. Dev Med Child Neurol. 2006; 48(6):424-8

22. Reimers J. The stability of the hip in children. A radiological study of the results of muscle surgery in cerebral palsy. Acta Orthop Scand Suppl. 1980: 184:1-100.

23. Bohannon RW, Smith MB. Interrater reliability of a modified Ashworth scale of muscle spasticity. Phys Ther. 1987;67(2):206-7.

24. Meseguer-Henarejos AB, Sanchez-Meca J, Lopez-Pina JA, Carles-Hernandez $\mathrm{R}$. Inter- and intra-rater reliability of the modified Ashworth scale: a systematic review and meta-analysis. Eur J Phys Rehabil Med. 2017. 
25. Manual till CPUP - Fysioterapeuter. http://cpup.se/wp-content/uploads/ 2017/01/FT-manual-2017.pdf. Accessed 12 September 2017. .

26. Ranstam J. Repeated measurements, bilateral observations and pseudoreplicates, why does it matter? Osteoarthr Cartil. 2012;20(6):473-5.

27. IBM Corp. Released 2016. IBM SPSS Statistics for Macintosh, Version 24.0. Armonk, NY: IBM Corp.

28. Westbom L, Rimstedt A, Nordmark E. Assessments of pain in children and adolescents with cerebral palsy: a retrospective population-based registry study. Dev Med Child Neurol. 2017;59(8):858-63.

29. Hodgkinson I, Jindrich ML, Duhaut P, Vadot JP, Metton G, Berard C. Hip pain in 234 non-ambulatory adolescents and young adults with cerebral palsy: a cross-sectional multicentre study. Dev Med Child Neurol. 2001;43(12):806-8.

30. Hägglund G, Wagner P. Spasticity of the gastrosoleus muscle is related to the development of reduced passive dorsiflexion of the ankle in children with cerebral palsy: a registry analysis of 2,796 examinations in 355 children. Acta Orthop. 2011;82(6):744-8.

31. Hadden $\mathrm{KL}$, LeFort $\mathrm{S}$, O'Brien M, Coyte PC, Guerriere DN. A comparison of observers' and self-report pain ratings for children with cerebral palsy. J Dev Behav Pediatr. 2015:36(1):14-23.

Ready to submit your research? Choose BMC and benefit from:

- fast, convenient online submission

- thorough peer review by experienced researchers in your field

- rapid publication on acceptance

- support for research data, including large and complex data types

- gold Open Access which fosters wider collaboration and increased citations

- maximum visibility for your research: over $100 \mathrm{M}$ website views per year

At $\mathrm{BMC}$, research is always in progress.

Learn more biomedcentral.com/submissions 